\title{
SHARPENED FORMS FOR DRIVING POINT IMPEDANCE FUNCTIONS AT BOUNDARY OF RIGHT HALF PLANE
}

\section{Bülent Nafi ÖRNEK ${ }^{1 *}$, Timur DÜZENLí2}

${ }^{1}$ Amasya Üniversitesi, Mühendislik-Mimarlık Fakültesi, Bilgisayar Mühendisliği Bölümü, Amasya, Türkiye

${ }^{2}$ Amasya Üniversitesi, Mühendislik-Mimarlık Fakültesi, Elektrik-Elektronik Mühendisliği Bölümü, Amasya, Türkiye

\begin{tabular}{|c|c|}
\hline Keywords & Abstract \\
\hline $\begin{array}{l}\text { Analytic function, } \\
\text { Schwarz lemma, } \\
\text { Positive real function, } \\
\text { Driving point, } \\
\text { Impedance function, } \\
\text { Boundary analysis. }\end{array}$ & $\begin{array}{l}\text { Driving point impedance functions (DPIFs) are frequently used in electrical } \\
\text { engineering, and they represent characteristic properties of various types of circuits } \\
\text { such as RL, RC, LC and RLC networks. In this paper, boundary analysis of driving point } \\
\text { impedance functions are investigated using Schwarz lemma. Assuming that the } \\
\text { driving point impedance function, } Z(s) \text {, is given as } Z(s)=\frac{A}{2}+c_{p}(s-1)^{p}+c_{p+1}(s- \\
1)^{p+1}+\ldots \text { and it is analytic in the right half of the s-plane, novel boundaries are } \\
\text { obtained for }\left|Z^{\prime}(0)\right| \text {. Accordingly, it is aimed to obtain novel inequalities which } \\
\text { presents higher boundaries for }\left|Z^{\prime}(0)\right| \text { and derive novel generic driving point } \\
\text { impedace functions by performing extremal analysis of these obtained inequalities. It } \\
\text { is also aimed to investigate how }\left|Z^{\prime}(s)\right| \text { can be interpreted when it is considered at the } \\
\text { boundary. According to simulation results, frequency characteristics of obtained } \\
\text { driving point impedance functions can be used to design of multi-notch filters which } \\
\text { are localized at certain frequency values. }\end{array}$ \\
\hline
\end{tabular}

\section{SAĞ YARI DÜZLEMİN SINIRINDAKİ SÜREN NOKTA EMPEDANS FONKSIYONLARI İÇIN KESKINLEŞTIRILMIŞ FORMLAR}

\author{
Anahtar Kelimeler \\ Analitik fonksiyon, \\ Schwarz lemmasi, \\ Pozitif reel fonksiyon, \\ Süren nokta \\ Empedans fonksiyonu, \\ Sinir analizi.
}

\begin{abstract}
Öz
Süren nokta empedans fonksiyonları (SNEF), elektrik mühendisliğinde sıklıkla kullanılmaktadır ve RL, RC, LC, ve RLC ağları gibi farklı tipteki devrelerin karakteristik özelliklerini temsil etmektedirler. Bu çalışmada, süren nokta empedans fonksiyonlarının sınır analizi, Schwarz lemması kullanılarak araștırılmaktadır. $Z(s)$ süren nokta empedans fonksiyonunun $Z(s)=\frac{A}{2}+c_{p}(s-$ $1)^{p}+c_{p+1}(s-1)^{p+1}+\ldots$ yapısında olduğu ve sağ yarı s-düzleminde analitik olduğu varsayılarak, $\left|Z^{\prime}(0)\right|$ için yeni sınırlar belirlenmektedir. Buna göre, $\left|Z^{\prime}(0)\right|$ için yeni üst sinırlar temsil eden eşitsizlikler türetilmesi ve bu eşitsizliklerin ekstremal analizi ile yeni genel süren nokta empedans fonksiyonları elde edilmesi amaçlanmaktadır. Ayrıca, sınırda olduğu düşünüldüğü takdirde, $\left|Z^{\prime}(s)\right|$ 'nin nasıl yorumlanacağı meselesinin çözülmesi de hedeflenmektedir. Benzetim sonuçlarına göre, elde edilen süren nokta empedans fonksiyonlarının frekans karakteristikleri, belli frekanslarda konumlanmış çok çentikli süzgeçlerin tasarlanması için kullanilabilmektedir.
\end{abstract}

\section{Cite}

Örnek, B. N., Düzenli, T., (2021). Sharpened Forms for Driving Point Impedance Functions at Boundary of Right Half Plane, Journal of Engineering Sciences and Design, 9(4), 1093-1105.

\footnotetext{
*Corresponding author: nafiornek@gmail.com,nafi.ornek@amasya.edu.tr,+90-358-211-5005
} 


\begin{tabular}{l|l|l}
\hline Yazar Kimliği / Author ID (ORCID Number) & \multicolumn{3}{|l}{ Makale Süreci / Article Process } \\
\hline B. N. Örnek, 0000-0001-7109-230X & Başvuru Tarihi / Submission Date & 30.05 .2021 \\
T. Düzenli, 0000-0003-0210-5626 & Revizyon Tarihi / Revision Date & 08.06 .2021 \\
& Kabul Tarihi / Accepted Date & 05.07 .2021 \\
& Yayım Tarihi / Published Date & 20.12 .2021 \\
\hline
\end{tabular}

\section{Introduction}

Driving point impedance functions (DPIFs) are frequently used in electrical engineering to represent spectral characteristics of RL, RC, LC and RLC circuits. Mathematically, DPIFs satisfy the properties of positive real functions (PRFs). Accordingly, the DPIF $Z(s)$, where s represents the complex frequency parameter, $s=\gamma+i w$, is analytic and single valued in $\Re s \geq 0$ except possibly for poles on the axis of imaginaries. Also, $Z(\bar{s})=\overline{Z(s)}$ and $\mathfrak{R} Z(s) \geq 0$, in $\mathfrak{R} s \geq 0$ (Reza, 1962).

In this paper, boundary analysis of DPIFs is performed by considering the derivative of Z(s) evaluated at zero, i.e. $Z^{\prime}(0)$. Accordingly, it is aimed to obtain novel inequalities which presents higher boundaries for $\left|Z^{\prime}(0)\right|$ and derive new DPIFs by performing sharpness analysis of these inequalities. Also, we aim to address the issue of how canbe interpreted $\left|Z^{\prime}(s)\right|$ when it is considered at the boundary. It may seem that evaluation of $\left|Z^{\prime}(0)\right|$ at boundary may narrow the results, however the analysis at the origin is a requirement which is caused by the nature of the considered problem.

Investigation of derivative of DPIFs is still a hot topic in the literature although the pioneer studies are back to 1930s. As one the pioneer works, Van Der Pol used the derivative of DPIFs to establish a relation between electrical and magnetic energy (Van Der Pol, 1937). In another work, Hazony showed that it is possible to utilize the DPIFs for gyrator design (Hazony, 1963). Theoretical analysis of positive real derivatives of DPIFs is given by (Krueger and Brown, 1969) where it's proved that the derivative of an RC driving point admittance is positive real under certain coefficient conditions. There are also other studies on boundary analysis of DPIFs using Schwarz lemma in the literature (Örnek and Düzenli, 2018; 2019).

The rest of the paper is organized as follows: Preliminary Considerations are given in Section II. In the next section, Main Results are presented with simulative findings. At the end, Conclusions are given in Section IV.

\section{Preliminary Considerations}

Let us consider a function $h(z)$ an analytic in the unit disc $E=\{z:|z|<1\}$. Schwarz's Lemma, which is a consequence of the Maximum Principle, says that if $h: E \rightarrow E$ is analytic with $h(z)=a_{p} z^{p}+a_{p+1} z^{p+1}+\ldots$, then $|h(z)| \leq|z|^{p}$, for every $z \in E$ and thus $\left|a_{p}\right| \leq 1$. In addition, if the equality $|h(z)|=|z|$ holds for any $z \neq 0$, or $\left|h^{\prime}(0)\right|=1$ then $f$ is a rotation, that is, $h(z)=z^{p} e^{i \theta}, \theta$ real (Dineen, 2016).

On the other hand, in the book (Kresin and Maz'ja, 2007), Sharp Real-Parts Theorem's (in particular Carathéodory's inequalities), which are frequently used in the theory of entire functions and analytic function theory, have been studied. Also, a boundary version of the Carathéodory's inequality is considered in unit disc and novel results are obtained in (Örnek, 2015). Mercer prove a version of the Schwarz lemma where the images of two points are known (Mercer, 1997). Also, he considers some Schwarz and Carathéodory inequalities at the boundary, as consequences of a lemma due to Rogosinski (Mercer, 2018a). In addition, he obtain an new boundary Schwarz lemma, for analytic functions mapping the unit disk to itself (Mercer, 2018b). At first, as in Schwarz lemma, Carathéodory's inequality at right half plane for positive real functions will be presented.

In Fig. 1, positive real $Z(s)$ function is mapped from right half plane to unit disc. In this way, $\vartheta(z)$ function has been obtained where it maps the unit disc to unit disc. 


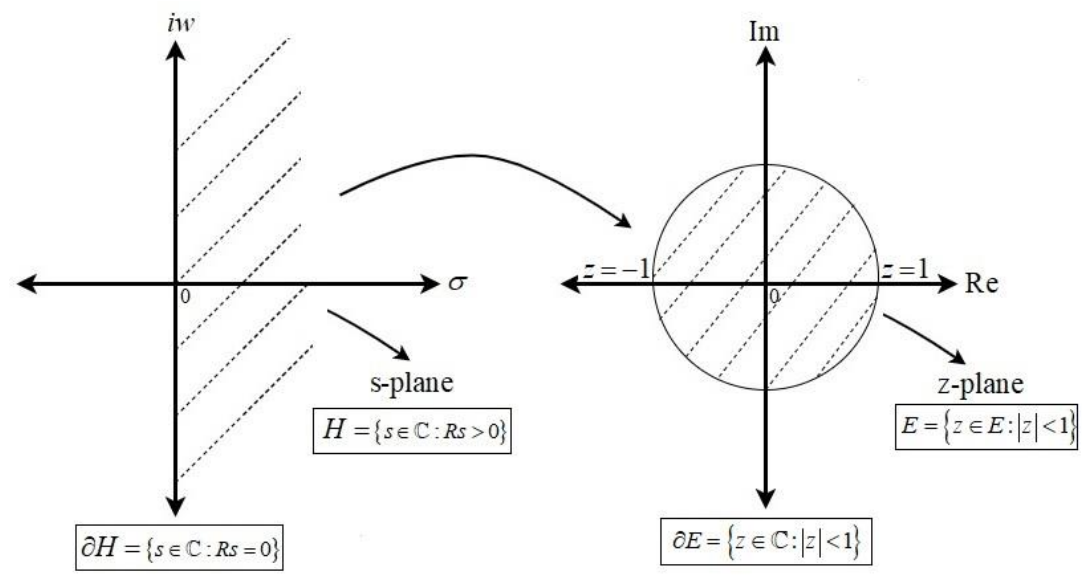

Figure 1. Mapping from RHP of $s$-domain $(H)$ to unit disc in $z$-domain $(E)$.

Let $Z(s)=\frac{A}{2}+b_{p}(s-1)^{p}+b_{p+1}(s-1)^{p+1}+\ldots$ be a positive real function with $0<\Re Z(s) \leq A$ for $\Re s \geq 0$ and consider the function

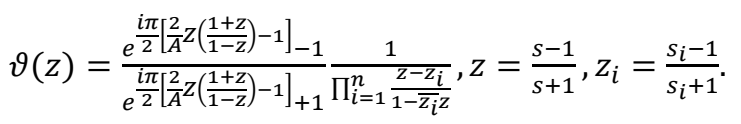

Here, $\vartheta(z)$ is an analytic function in $E, \vartheta(0)=0$ and $|\vartheta(z)|<1$ for $z \in E$. From (1.1), we take

$$
\begin{aligned}
& \vartheta(z)=\frac{\frac{i \pi}{2}\left(\frac{b_{p}}{A} \frac{2^{p+1} z^{p}}{(1-z)^{p}}+\frac{2^{p+2} b_{p+1} z^{p+1}}{A(1-z)^{p+1}}+\ldots\right)+\frac{1}{2}\left(\frac{i \pi}{2}\left(\frac{b_{p}}{A} \frac{2^{p+1} z^{p}}{(1-z)^{p}}+\frac{2^{p+2} b_{p+1} z^{p+1}}{A(1-z)^{p+1}}+\ldots\right)\right)^{2}+\ldots}{\left(2+\frac{i \pi}{2}\left(\frac{b_{p}}{A} \frac{2^{p+1} z^{p}}{(1-z)^{p}}+\frac{2^{p+2} b_{p+1} z^{p+1}}{A(1-z)^{p+1}}+\ldots\right)+\frac{1}{2}\left(\frac{i \pi}{2}\left(\frac{b_{p}}{A} \frac{2^{p+1} z^{p}}{(1-z)^{p}}+\frac{2^{p+2} b_{p+1} z^{p+1}}{A(1-z)^{p+1}}+\ldots\right)\right)^{2}+\ldots\right)} \frac{1}{\prod_{i=1}^{n} \frac{z-z_{i}}{1-\bar{z}_{i} z}} \\
& \frac{\vartheta(z)}{Z^{p}}=\frac{\frac{i \pi}{2}\left(\frac{b_{p}}{A} \frac{2^{p+1}}{(1-z)^{p}}+\frac{2^{p+2} b_{p+1} Z}{A(1-z)^{p+1}}+\ldots\right)+\frac{1}{2} Z^{p}\left(\frac{i \pi}{2}\left(\frac{b_{p}}{A} \frac{2^{p+1}}{(1-z)^{p}}+\frac{2^{p+2} b_{p+1} Z}{A(1-z)^{p+1}}+\ldots\right)\right)^{2}+\ldots}{\left(2+\frac{i \pi}{2}\left(\frac{b_{p}}{A} \frac{2^{p+1} z^{p}}{(1-z)^{p}}+\frac{2^{p+2} b_{p+1} z^{p+1}}{A(1-z)^{p+1}}+\ldots\right)+\frac{1}{2}\left(\frac{i \pi}{2}\left(\frac{b_{p}}{A} \frac{2^{p+1} z^{p}}{(1-z)^{p}}+\frac{2^{p+2} b_{p+1} z^{p+1}}{A(1-z)^{p+1}}+\ldots\right)\right)^{2}+\ldots\right)} \frac{1}{\prod_{i=1}^{n} \frac{z-z_{i}}{1-\bar{z}_{i} z}}
\end{aligned}
$$

and passing to limit $(z \rightarrow 0)$ in the last equality and from Schwarz lemma yields

$$
\left|b_{p}\right| \leq \frac{2 A}{\pi 2^{p}} \prod_{i=1}^{n}\left|z_{i}\right|=\frac{2 A}{\pi 2^{p}} \prod_{i=1}^{n}\left|\frac{s_{i}-1}{s_{i}+1}\right| .
$$

This result is sharp with the function

$$
Z(s)=\frac{A}{2}\left(1+\frac{2}{i \pi} \ln \left(\frac{1+\left(\frac{s-1}{s+1}\right)^{p} \prod_{i=1}^{n} \frac{\frac{s-1}{s+1}-\frac{s_{i}-1}{s_{i}+1}}{1-\frac{s_{i}-1}{s-1}}}{1-\left(\frac{s-1}{s+1}\right)^{p} \prod_{i=1}^{n} \frac{\frac{s-1}{s+1}-\frac{s_{i}-1}{s_{i}+1}}{1-\frac{s_{i}-1}{s-1}}}\right)\right)
$$

We thus obtain the following lemma.

Lemma 1 Let $Z(s)=\frac{A}{2}+b_{p}(s-1)^{p}+b_{p+1}(s-1)^{p+1}+\ldots ., p \geq 1$ be a positive real function with $0<\Re Z(s) \leq A$ for $\Re s \geq 0$. Assume that $s_{1}, \ldots, s_{n}$ are points in right half plane that are different from $s=1$ with $Z\left(s_{i}\right)=\frac{A}{2}$. Then we have the inequality 


$$
\left|b_{p}\right| \leq \frac{2 A}{\pi 2^{p}} \prod_{i=1}^{n}\left|\frac{s_{i}-1}{s_{i}+1}\right| .
$$

The inequality (1.2) is sharp, with equality for the function

$$
Z(s)=\frac{A}{2}\left(1+\frac{2}{i \pi} \ln \left(\frac{1+\left(\frac{s-1}{s+1}\right)^{p} \prod_{i=1}^{n} \frac{\frac{s-1}{s+1} \frac{s_{i}-1}{s_{i}+1}}{1-\frac{s_{i}-1 s-1}{s_{i}+1 s+1}}}{1-\left(\frac{s-1}{s+1}\right)^{p} \prod_{i=1}^{n} \frac{\frac{s-1}{s+1}-\frac{s_{i}-1}{s_{i}+1}}{1-\frac{\overline{s_{i}-1} s-1}{s_{i}+1 s+1}}}\right)\right) .
$$

Frequency characteristic graphics related to $Z(s)$ obtained in Lemma 1 are given in Fig. 2. For simplicity, it is assumed that parameters of $Z(s)$ are given as $A=1$ and $s_{1}=s_{2}=s_{3}=s_{4}=1$. According to Fig. 2, various filter structures can be possibly determined using the obtained DPIF. It is common for all filters that they have a spiky structure at low frequency values where the number of the spikes increases proportionally with $n$ parameter. It can be observed from the figures that $p$ parameter has no effect on the number of the spikes however it slightly changes the smoothness of the spikes.
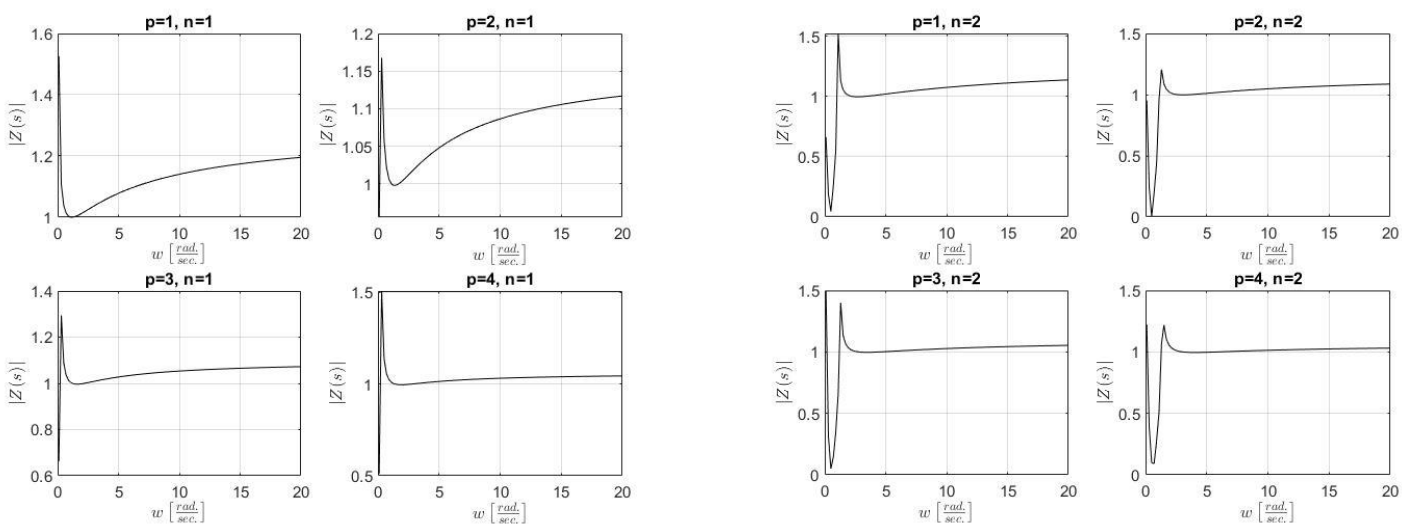

a. $n=1$

b. $n=2$
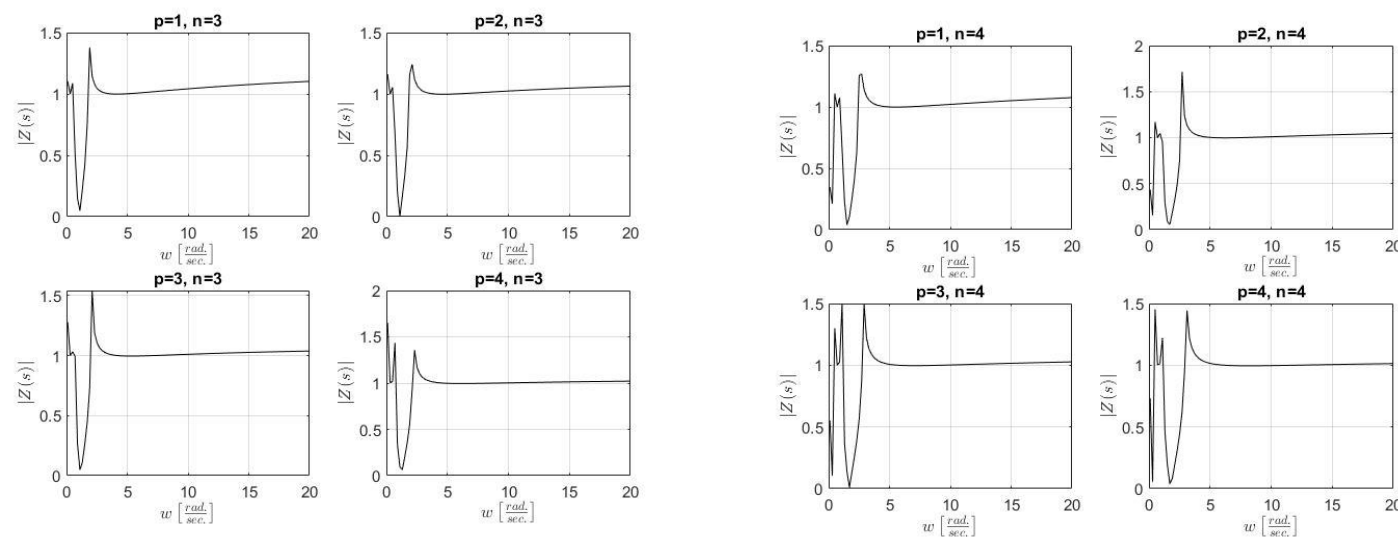

c. $n=3$

d. $n=4$

Figure 2. Frequency magnitude graphic of $Z(s)$ function obtained in Lemma 1 for different $n$ and different $p$ values.

Since the area of applicability of Schwarz Lemma is quite wide, there exist many studies about it. Some of these studies is called the boundary version of Schwarz Lemma. An important result of Schwarz lemma was given by Osserman (Boas, 2010, Dubinin, 2004; Mercer, 2018a; Osserman, 2000; Reza, 1962). 


\section{Main Results}

In this section, a boundary analysis results for the derivative of Positive Real function are presented. From the definition of PRFs, we can state that $Z(s)$ is analytic and single valued on the right half of the $s$-plane. In the following theorem, we establish lower bounds on the derivative of $Z(0)$ for positive real functions with $Z(0)=A$.

Theorem 1 Let $Z(s)=\frac{A}{2}+b_{p}(s-1)^{p}+b_{p+1}(s-1)^{p+1}+\ldots ., p \geq 2$ be a positive real function with $0<\Re Z(s) \leq A$ for $\mathfrak{R} s \geq 0$ that is also analytic at the point $s=0$ of the imaginary axis with $Z(0)=$ A. Assume that $s_{1}, \ldots, s_{n}$ are points in right half plane that are different from $s=1$ with $Z\left(s_{i}\right)=\frac{A}{2}$. Then

$$
\left|Z^{\prime}(0)\right| \geq \frac{2 A}{\pi}\left(p+\sum_{i=1}^{n} \frac{\Re s_{i}}{\left|s_{i}\right|^{2}}+\frac{2 A \prod_{i=1}^{n}\left|\frac{s_{i}-1}{s_{i}+1}\right|-\pi 2^{p}\left|b_{p}\right|}{2 A \prod_{i=1}^{n}\left|\frac{s_{i}-1}{s_{i}+1}\right|+\pi 2^{p}\left|b_{p}\right|}\right) .
$$

The results (2.1) is sharp for the function given by

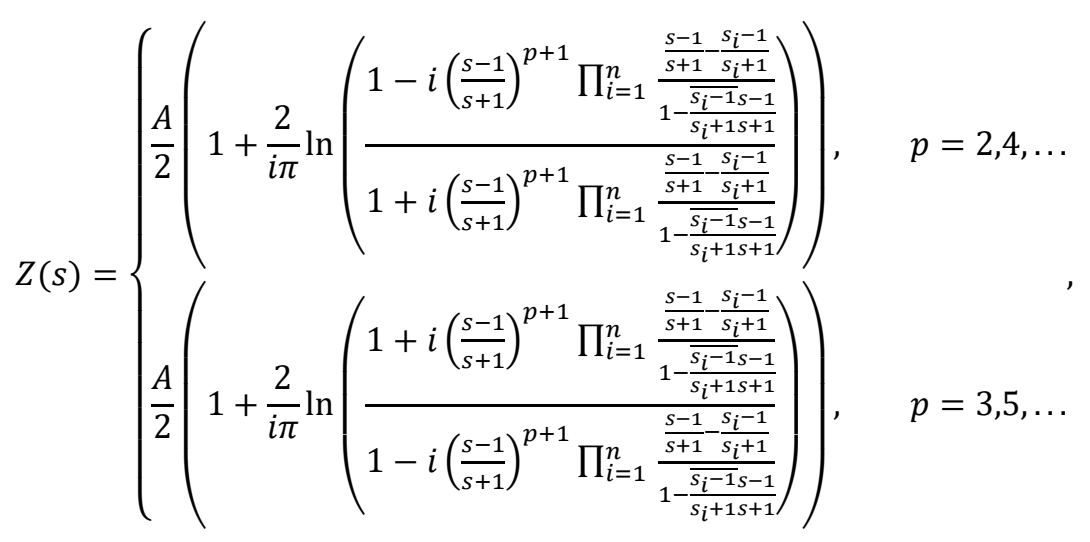

where $s_{1}, \ldots, s_{n}$ are positive real numbers.

Proof. Consider the function

$$
f(z)=\frac{e^{\frac{i \pi}{2}\left[\frac{2}{A} Z\left(\frac{1+z}{1-z}\right)-1\right]}-1}{e^{\frac{i \pi}{2}\left[\frac{2}{A} Z\left(\frac{1+z}{1-z}\right)-1\right]}+1} \text { and } B(z)=\prod_{i=1}^{n} \frac{z-z_{i}}{1-\overline{z_{i}} z}
$$

$f(z)$ and $B(z)$ are analytic in $E$, and $|f(z)|<1,|B(z)|<1$ for $z \in E$. By the maximum principle for each $z \in E$, we have $|f(z)|<|B(z)|$.

The composite function

$$
m(z)=\frac{f(z)}{B(z)}
$$

is analytic in the unit $\operatorname{disc} E,|m(z)|<1$ for $z \in E, m(0)=0$ and $|m(-1)|=1$ for $-1 \in \partial E$. Moreover, it can be seen that

$$
\frac{(-1) f^{\prime}(-1)}{f(-1)}=\left|f^{\prime}(-1)\right| \geq\left|B^{\prime}(-1)\right|=\frac{(-1) B^{\prime}(-1)}{B(-1)}
$$

Besides, with the simple calculations, we get

$$
\left|B^{\prime}(-1)\right|=\sum_{i=1}^{n} \frac{1-\left|z_{i}\right|^{2}}{\left|1+z_{i}\right|^{2}}
$$


Therefore, $m(z)$ function satisfies the assumptions of the Schwarz lemma on the boundary, we obtain

$$
\begin{aligned}
& p+\frac{1-\left|c_{p}\right|}{1-\left|c_{p}\right|} \leq\left|m^{\prime}(-1)\right|=\left|\frac{(-1) f^{\prime}(-1)}{f(-1)}-\frac{(-1) B^{\prime}(-1)}{B(-1)}\right| \\
& =\left|f^{\prime}(-1)\right|-\left|B^{\prime}(-1)\right| \\
& =\left|\frac{\frac{4 i \pi}{A 4} Z^{\prime}(0) e^{\frac{i \pi}{2}\left[\frac{2}{A} Z(0)-1\right]}}{\left(e^{\frac{i \pi}{2}\left[\frac{2}{A} Z(0)-1\right]}+1\right)^{2}}\right|-\sum_{i=1}^{n} \frac{1-\left|z_{i}\right|^{2}}{\left|1+z_{i}\right|^{2}} \\
& =\frac{\pi}{2 A}\left|Z^{\prime}(0)\right|-\sum_{i=1}^{n} \frac{1-\left|z_{i}\right|^{2}}{\left|1+z_{i}\right|^{2}} .
\end{aligned}
$$

Since

we take

$$
\left|c_{p}\right|=\frac{\pi 2^{p}}{2 A \prod_{i=1}^{n}\left|z_{i}\right|}\left|b_{p}\right|,
$$

$$
p+\frac{1-\frac{\pi 2^{p}}{2 A \prod_{i=1}^{n}\left|z_{i}\right|}\left|b_{p}\right|}{1-\frac{\pi 2^{p}}{2 A \prod_{i=1}^{n}\left|z_{i}\right|}\left|b_{p}\right|} \leq \frac{\pi}{2 A}\left|Z^{\prime}(0)\right|-\sum_{i=1}^{n} \frac{1-\left|z_{i}\right|^{2}}{\left|1+z_{i}\right|^{2}}
$$

and

$$
p+\frac{2 A \prod_{i=1}^{n}\left|z_{i}\right|-\pi 2^{p}\left|b_{p}\right|}{2 A \prod_{i=1}^{n}\left|z_{i}\right|+\pi 2^{p}\left|b_{p}\right|}+\sum_{i=1}^{n} \frac{1-\left|z_{i}\right|^{2}}{\left|1+z_{i}\right|^{2}} \leq \frac{\pi}{2 A}\left|Z^{\prime}(0)\right| .
$$

Now, we shall show that the inequality (2.1) is sharp. Let

$$
Z\left(\frac{1+z}{1-z}\right)=\frac{A}{2}\left(1+\frac{2}{i \pi} \ln \left(\frac{1-i(z)^{p+1} \prod_{i=1}^{n} \frac{z-z_{i}}{1-\overline{z_{i}} Z}}{1+i(z)^{p+1} \prod_{i=1}^{n} \frac{z-z_{i}}{1-\overline{z_{i}} z}}\right)\right), \quad p=2,4, \ldots, z=\frac{s-1}{s+1}, z_{i}=\frac{s_{i}-1}{s_{i}+1} .
$$

Then

$$
\begin{gathered}
\frac{2}{(1-z)^{2}} Z^{\prime}\left(\frac{1+z}{1-z}\right)=\frac{A}{i \pi} \frac{-\left((p+1) i z^{p} \prod_{i=1}^{n} \frac{z-z_{i}}{1-\overline{z_{i} z}}+i(z)^{p+1} \sum_{i=1}^{n} \frac{1-\left|z_{i}\right|^{2}}{\left(1-\overline{z_{z}} z\right)\left(z-z_{i}\right)} \prod_{i=1}^{n} \frac{z-z_{i}}{1-\overline{z_{i} z}}\right) k}{\left(1+i(z)^{p+1} \prod_{i=1}^{n} \frac{z-z_{i}}{1-\overline{z_{i} z}}\right)\left(1-i(z)^{p+1} \prod_{i=1}^{n} \frac{z-z_{i}}{1-\overline{z_{i} z} z}\right)} \\
-\frac{A}{i \pi} \frac{\left((p+1) i z^{p} \prod_{i=1}^{n} \frac{z-z_{i}}{1-\overline{\bar{z}_{i} z}}+i(z)^{p+1} \sum_{i=1}^{n} \frac{1-\left|z_{i}\right|^{2}}{\left(1-\overline{z_{i}} z\right)\left(z-z_{i}\right)} \prod_{i=1}^{n} \frac{z-z_{i}}{1-\overline{z_{i} z}}\right) l}{\left(1+i(z)^{p+1} \prod_{i=1}^{n} \frac{z-z_{i}}{1-\overline{\bar{z}_{i} z}}\right)\left(1-i(z)^{p+1} \prod_{i=1}^{n} \frac{z-z_{i}}{1-\overline{\bar{z}_{i} z}}\right)}
\end{gathered}
$$

where

$$
k=1+i(z)^{p+1} \prod_{i=1}^{n} \frac{z-z_{i}}{1-\overline{z_{i}} Z}
$$

and 


$$
l=1-i(z)^{p+1} \prod_{i=1}^{n} \frac{z-z_{i}}{1-\overline{z_{i}} z}
$$

For $z=-1$ and since $s_{1}, \ldots, s_{n}$ are positive real numbers, we obtain

$$
\begin{aligned}
Z^{\prime}(0) & =\frac{2 A}{i \pi} \frac{-\left(-(p+1) i(-1)^{p}+i(-1)^{p+1} \sum_{i=1}^{n} \frac{1-z_{i}}{1+z_{i}}\right)\left(1-i(-1)^{p+1}\right)}{\left(1-i(-1)^{p+1}\right)\left(1+i(-1)^{p+1}\right)} \\
- & \frac{2 A}{i \pi} \frac{\left(-(p+1) i(-1)^{p}+i(-1)^{p+1} \sum_{i=1}^{n} \frac{1-z_{i}}{1+z_{i}}\right)\left(1+i(-1)^{p+1}\right)}{\left(1-i(-1)^{p+1}\right)\left(1+i(-1)^{p+1}\right)}, \\
Z^{\prime}(0) & =\frac{2 A}{i \pi} \frac{-\left(-(p+1) i(-1)^{p}+i(-1)^{p+1} \sum_{i=1}^{n} \frac{1-z_{i}}{1+z_{i}}\right)\left(1-i(-1)^{p+1}\right)}{2} \\
- & \frac{2 A}{i \pi} \frac{\left(-(p+1) i(-1)^{p}+i(-1)^{p+1} \sum_{i=1}^{n} \frac{1-z_{i}}{1+z_{i}}\right)\left(1+i(-1)^{p+1}\right)}{2}
\end{aligned}
$$

and

$$
\left|Z^{\prime}(0)\right|=\frac{2 A}{\pi}\left(p+1+\sum_{i=1}^{n} \frac{1-z_{i}}{1+z_{i}}\right)
$$

Similarly, let

$$
Z\left(\frac{1+z}{1-z}\right)=\frac{A}{2}\left(1+\frac{2}{i \pi} \ln \left(\frac{1+i(z)^{p+1} \prod_{i=1}^{n} \frac{z-z_{i}}{1-\overline{z_{i} z}}}{1-i(z)^{p+1} \prod_{i=1}^{n} \frac{z-z_{i}}{1-\overline{z_{i} z}}}\right)\right), \quad p=3,5, \ldots, z=\frac{s-1}{s+1}, z_{i}=\frac{s_{i}-1}{s_{i}+1}
$$

Then,

$$
\left|Z^{\prime}(0)\right|=\frac{2 A}{\pi}\left(p+1+\sum_{i=1}^{n} \frac{1-z_{i}}{1+z_{i}}\right)
$$

Also, since $z_{i}=\frac{s_{i}-1}{s_{i}+1}$, we take

$$
\left|Z^{\prime}(0)\right|=\frac{2 A}{\pi}\left(p+1+\sum_{i=1}^{n} \frac{1-\frac{s_{i}-1}{s_{i}+1}}{1+\frac{s_{i}-1}{s_{i}+1}}\right)=\frac{2 A}{\pi}\left(p+1+\sum_{i=1}^{n} \frac{1}{s_{i}}\right)
$$

In addition, since $\left|b_{p}\right|=0$, (2.1) holds.

In Figs. 3 and 4, frequency characteristic graphics are given for DPIF obtained in Theorem 1 for even and odd values of $p$, respectively. As in Lemma 1, again $n$ is the significant variable that determines the number of the spikes here. According to figures, notches have a sharper structure when $p$ takes odd values and they are smoother for even values of $p$. 

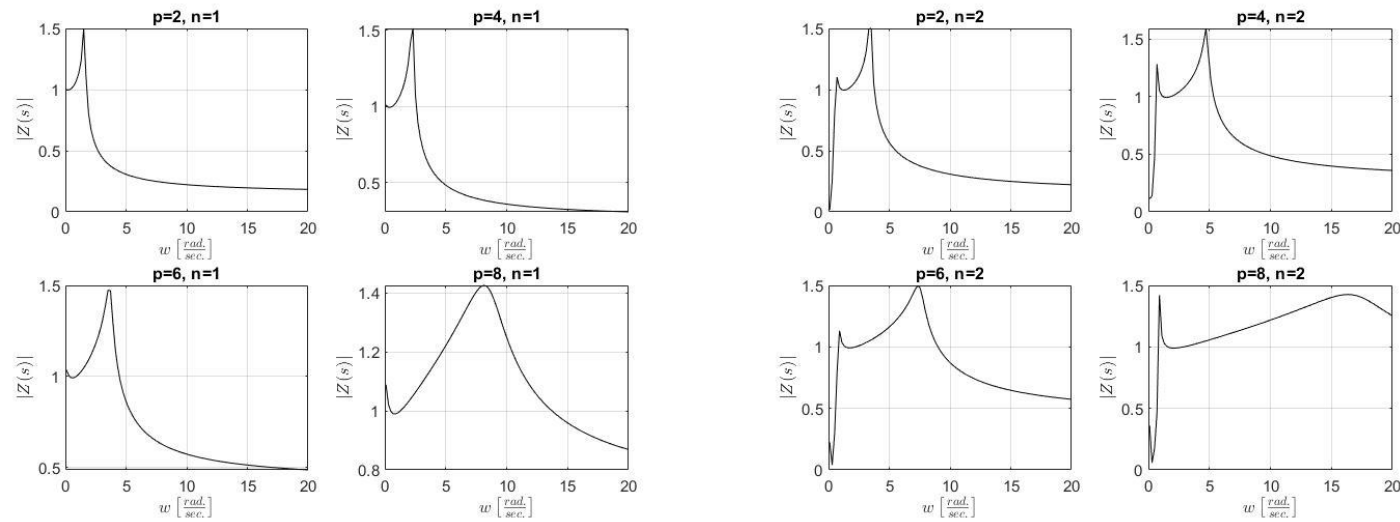

a. $n=1$
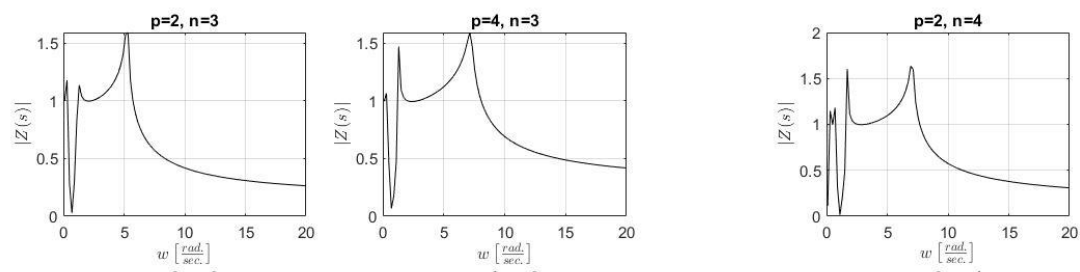

b. $n=2$
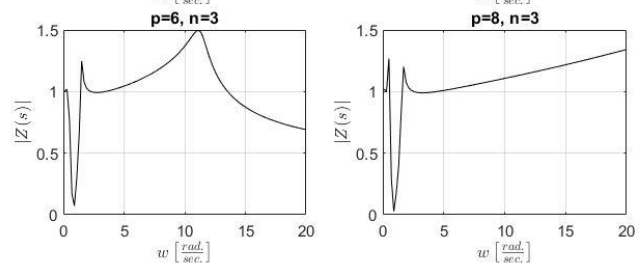

c. $n=3$
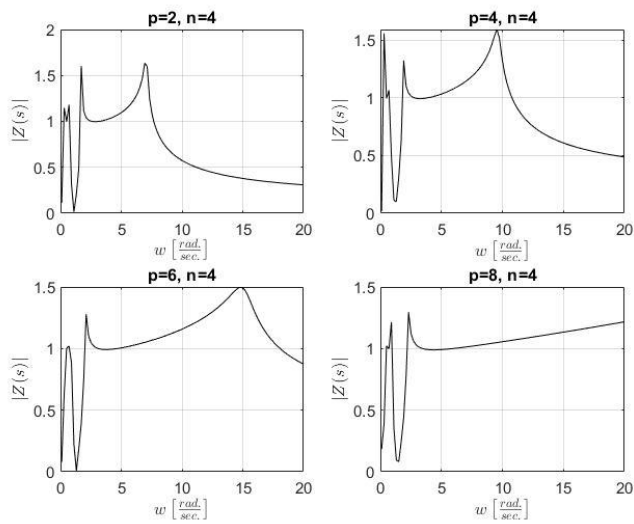

d. $n=4$

Figure 3. Frequency magnitude graphic of $Z(s)$ function obtained in Theorem 1 assuming that $p$ parameter takes even values. 

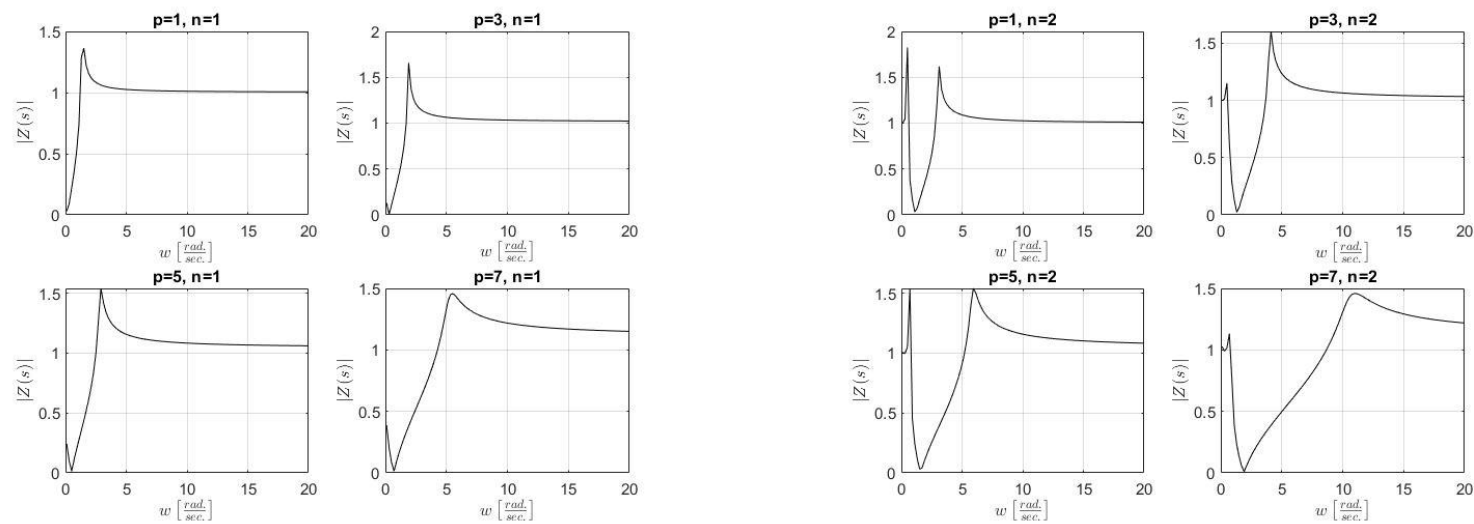

a. $n=1$
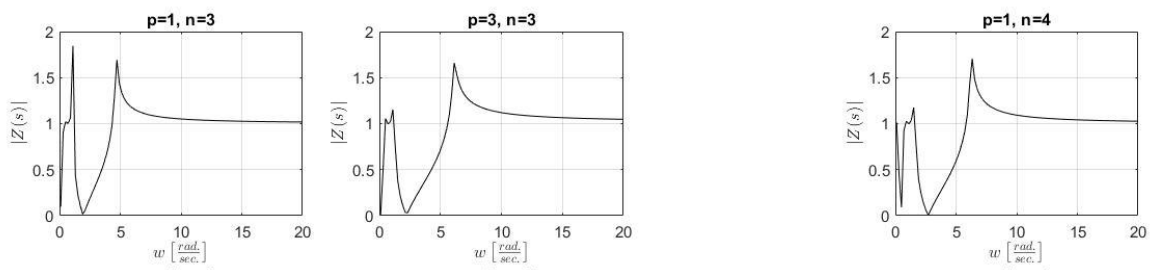

b. $n=2$
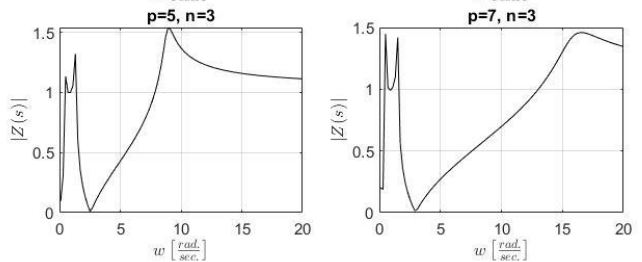

c. $n=3$
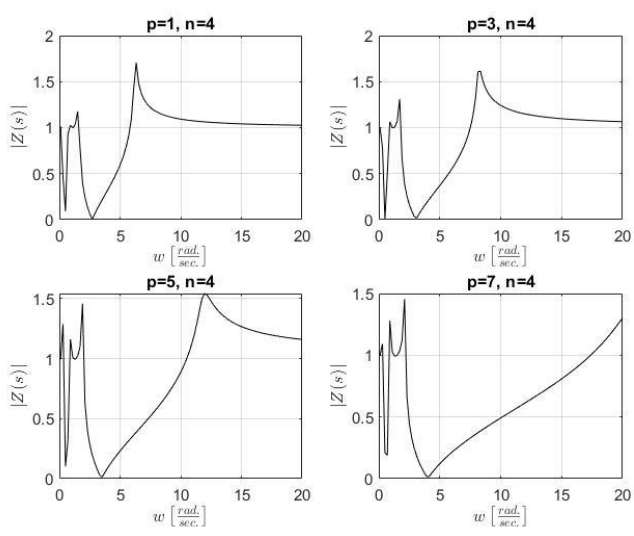

d. $n=4$

Figure 4. Frequency magnitude graphic of $Z(s)$ function obtained in Theorem 1 assuming that $p$ parameter takes odd values.

Theorem $2 \operatorname{Let} Z(s)=\frac{A}{2}+b_{p}(s-1)^{p}+b_{p+1}(s-1)^{p+1}+\ldots ., p \geq 2$ be a positive real function with $0<\Re Z(s) \leq A$ for $\Re s \geq 0$ that is also analytic at the point $s=0$ of the imaginary axis with $Z(0)=$ A. Suppose that $Z(s)$ has no points right half plane except $s=1$ and $b_{p}>0$. Then we have the inequality

and

$$
\left|Z^{\prime}(0)\right| \geq \frac{2 A}{\pi}\left(p-\frac{2 b_{p} \ln ^{2}\left(\frac{\pi 2^{p}}{2 A} b_{p}\right)}{2 b_{p} \ln \left(\frac{\pi 2^{p}}{2 A} b_{p}\right)+\left|p b_{p}+2 b_{p+1}\right|}\right)
$$

$$
\left|p b_{p}+2 b_{p+1}\right| \leq 2\left|b_{p} \ln \left(\frac{\pi 2^{p}}{2 A} b_{p}\right)\right|
$$

The equality in (2.3) occurs for the function

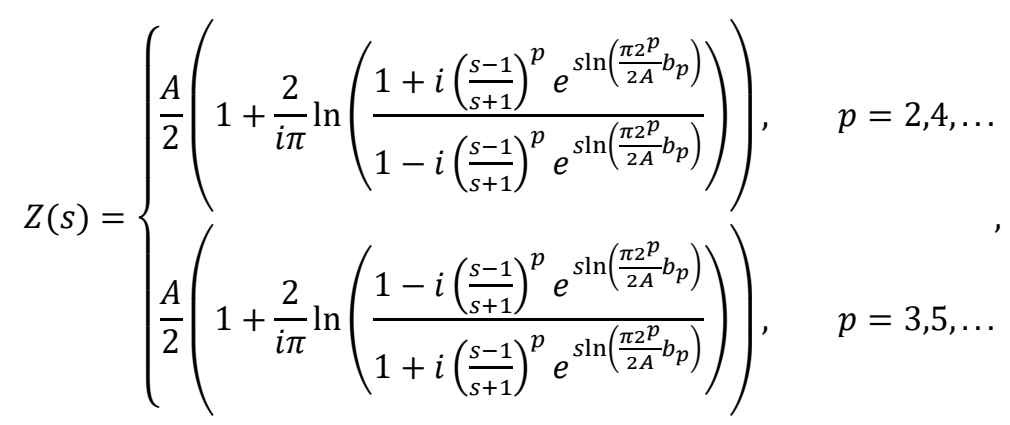

where $\ln \left(\frac{\pi 2^{p}}{2 A} b_{p}\right)<0$ and $b_{p}>0$. 
Proof. Let $b_{p}>0$ in the expression of the function $Z(s)$. Also, the function $Z(s)$ has no points in the right half plane except $s=1$ and $f(z)$ be as in the proof Theorem 1 . Consider the funtion

$$
m(z)=\frac{f(z)}{u(z)}
$$

where $u(z)=i z^{p}$ So, the maximum priciple implies that for each $z \in E$, we have $|f(z)| \leq|u(z)|$. Therefore, $|m(z)|<1$ for $|z|<1$. Thus, we obtain

$$
m(0)=\frac{\pi 2^{p}}{2 A} b_{p}
$$

Having in mind equality (2.4), we denote by $\ln m(z)$ the analytic branch of logarithm normalized by the condition

$$
\ln m(0)=\ln \left(\frac{\pi 2^{p}}{2 A} b_{p}\right)<0
$$

The auxiliary function

$$
g(z)=\frac{\ln m(z)-\ln m(0)}{\ln m(z)+\ln m(0)}
$$

is analytic in $E,|g(z)|<1$ for $z \in E, g(0)=0$ and $|g(-1)|=1$ for $-1 \in \partial E$. Therefore, from (1.3) for $p=1$, we obtain

$$
\begin{gathered}
\frac{2}{1+\left|g^{\prime}(0)\right|} \leq\left|g^{\prime}(-1)\right|=\frac{|2 \ln m(0)|}{|\ln m(-1)+\ln m(0)|^{2}}\left|\frac{m^{\prime}(-1)}{m(-1)}\right| \\
=\frac{-2 \ln m(0)}{\ln ^{2} m(0)+\arg ^{2} m(-1)}\left(\left|f^{\prime}(-1)\right|-\left|u^{\prime}(-1)\right|\right) \\
\leq \frac{-2}{\ln m(0)}\left(\frac{A}{\pi} \frac{\left|Z^{\prime}(0)\right|}{2}-p\right), \\
g^{\prime}(0)=\frac{m^{\prime}(0)}{2 m(0) \ln m(0)}=\frac{\left|p b_{p}+2 b_{p+1}\right|}{2 b_{p} \ln \left(\frac{\pi 2^{p}}{2 A} b_{p}\right)}
\end{gathered}
$$

and

$$
\frac{2}{1+\frac{\left|p b_{p}+2 b_{p+1}\right|}{2 b_{p} \ln \left(\frac{\pi 2^{p}}{2 A} b_{p}\right)}} \leq \frac{-2}{\ln \left(\frac{\pi 2^{p}}{2 A} b_{p}\right)}\left(\frac{A}{\pi} \frac{\left|Z^{\prime}(0)\right|}{2}-p\right) .
$$

Thus, we have the inequality (2.2). Similarly, the function $g(z)$ satisfies the assumtions of the Schwarz lemma, we take

$$
\begin{gathered}
1 \geq\left|g^{\prime}(0)\right|=\frac{|2 \ln m(0)|}{|\ln m(0)+\ln m(0)|^{2}}\left|\frac{m^{\prime}(0)}{m(0)}\right| \\
=\frac{-1}{2 \ln \left(\frac{\pi 2^{p}}{2 A} b_{p}\right)} \frac{\left|p b_{p}+2 b_{p+1}\right|}{b_{p}}
\end{gathered}
$$

and

$$
\left|p b_{p}+2 b_{p+1}\right| \leq 2\left|b_{p} \ln \left(\frac{\pi 2^{p}}{2 A} b_{p}\right)\right|
$$


Now we shall show that inequality (2.3) is sharp. Let

$$
Z\left(\frac{1+Z}{1-z}\right)=\frac{A}{2}\left(1+\frac{2}{i \pi} \ln \left(\frac{1+i z^{p} e^{\frac{1+z}{1-z} \ln \left(\frac{\pi 2^{p}}{2 A} b_{p}\right)}}{1-i z^{p} e^{\frac{1+z}{1-z} \ln \left(\frac{\pi 2^{p}}{2 A} b_{p}\right)}}\right)\right), \quad p=2,4, \ldots, z=\frac{s-1}{s+1}
$$

After simple calculations, we take

$$
e^{\frac{i \pi}{2}\left[\frac{2}{A} Z\left(\frac{1+z}{1-z}\right)-1\right]}-1=z^{p} \frac{2 i e^{\frac{1+z}{1-z} \ln \left(\frac{\pi 2}{2 A} b_{p}\right)}}{1-i z^{p} e^{\frac{1+z}{1-z} \ln \left(\frac{\pi 2}{2 A} b_{p}\right)}}=z^{p} W(z)
$$

Therefore,we have

$$
\begin{gathered}
w(z)=\frac{e^{\frac{i \pi}{2}\left[\frac{2}{A} z\left(\frac{1+z}{1-z}\right)-1\right]}-1}{z^{p}} \\
=\frac{i \pi}{2}\left(\frac{b_{p}}{A} \frac{2^{p+1}}{(1-z)^{p}}+\frac{2^{p+2} b_{p+1} z}{A(1-z)^{p+1}}+\ldots\right)+\frac{1}{2} z^{p}\left(\frac{i \pi}{2}\left(\frac{b_{p}}{A} \frac{2^{p+1}}{(1-z)^{p}}+\frac{2^{p+2} b_{p+1} z}{A(1-z)^{p+1}}+\ldots\right)\right)^{2}+\ldots
\end{gathered}
$$

and

$$
\left|w^{\prime}(0)\right|=\frac{\pi 2^{p}}{A}\left|p b_{p}+2 b_{p+1}\right|
$$

In addition, let

$$
w(z)=\frac{2 i e^{\frac{1+z}{1-z} \ln \left(\frac{\pi 2}{2 A} b_{p}\right)}}{1-i z^{p} e^{\frac{1+z}{1-z} \ln \left(\frac{\pi 2^{p}}{2 A} b_{p}\right)}} .
$$

Taking the derivative of the function $w(z)$, we get

$$
\begin{aligned}
& w^{\prime}(z)=2 i \frac{\frac{2}{(1-z)^{2}} \ln \left(\frac{\pi 2^{p}}{2 A} b_{p}\right) e^{\frac{1+z}{1-z} \ln \left(\frac{\pi 2^{p}}{2 A} b_{p}\right)}\left(1-i z^{p} e^{\frac{1+z}{1-z} \ln \left(\frac{\pi 2^{p}}{2 A} b_{p}\right)}\right)}{\left(1-i Z^{p} e^{\frac{1+z}{1-z} \ln \left(\frac{\pi 2^{p}}{2 A} b_{p}\right)}\right)^{2}} \\
& +i \frac{\left(p z^{p-1} e^{\frac{1+z}{1-z} \ln \left(\frac{\pi 2^{p} p}{2 A} b_{p}\right)}+\frac{2}{(1-z)^{2}} \ln \left(\frac{\pi 2^{p}}{2 A} b_{p}\right) e^{\frac{1+z}{1-z} \ln \left(\frac{\pi 2}{2 A} b_{p}\right)}\right) e^{\frac{1+z}{1-z} \ln \left(\frac{\pi 2^{2} p}{2 A} b_{p}\right)}}{\left(1-i z^{p} e^{\frac{1+z}{1-z} \ln \left(\frac{\pi 2^{p}}{2 A} b_{p}\right)}\right)^{2}}
\end{aligned}
$$

and

$$
\left|w^{\prime}(0)\right|=\frac{\pi 2^{p}}{A} 2\left|b_{p} \ln \left(\frac{\pi 2^{p}}{2 A} b_{p}\right)\right|
$$

Thus, we obtain

Similarly, for $p=3,5, \ldots$

$$
\left|p b_{p}+2 b_{p+1}\right|=2\left|b_{p} \ln \left(\frac{\pi 2^{p}}{2 A} b_{p}\right)\right| \text {. }
$$


In Figs. 5 and 6, frequency characteristic graphics of $Z(s)$ function obtained in Theorem 2 are given for even and odd values of $p$, respectively. Here, $A$ and $b_{p}$ values are assumed to be equal to 1 . According to Figs 5 and $6,|Z(s)|$ has an self-repeating structure which makes it possible to comment that the filters given here are sampled (discrete in time) analog filters since their frequency spectrum has a periodical structure.
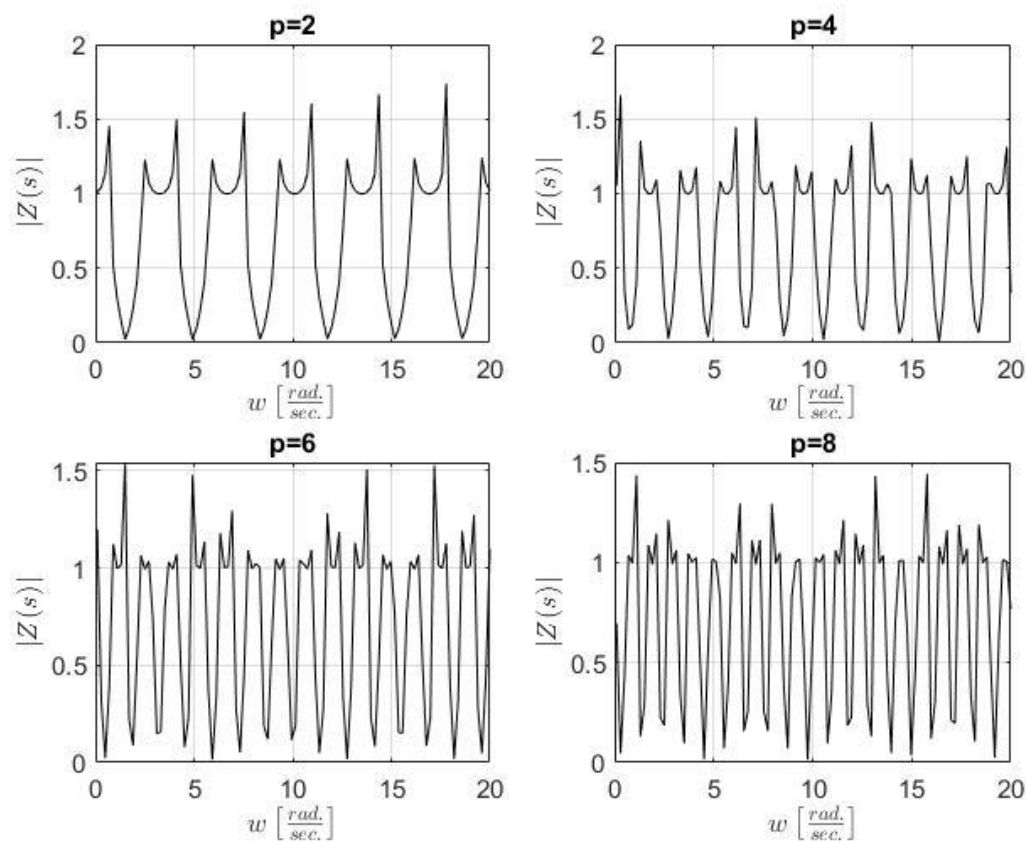

Figure 5. Frequency magnitude graphics of $Z(s)$ function obtained in Theorem 2 for even values of $p$.
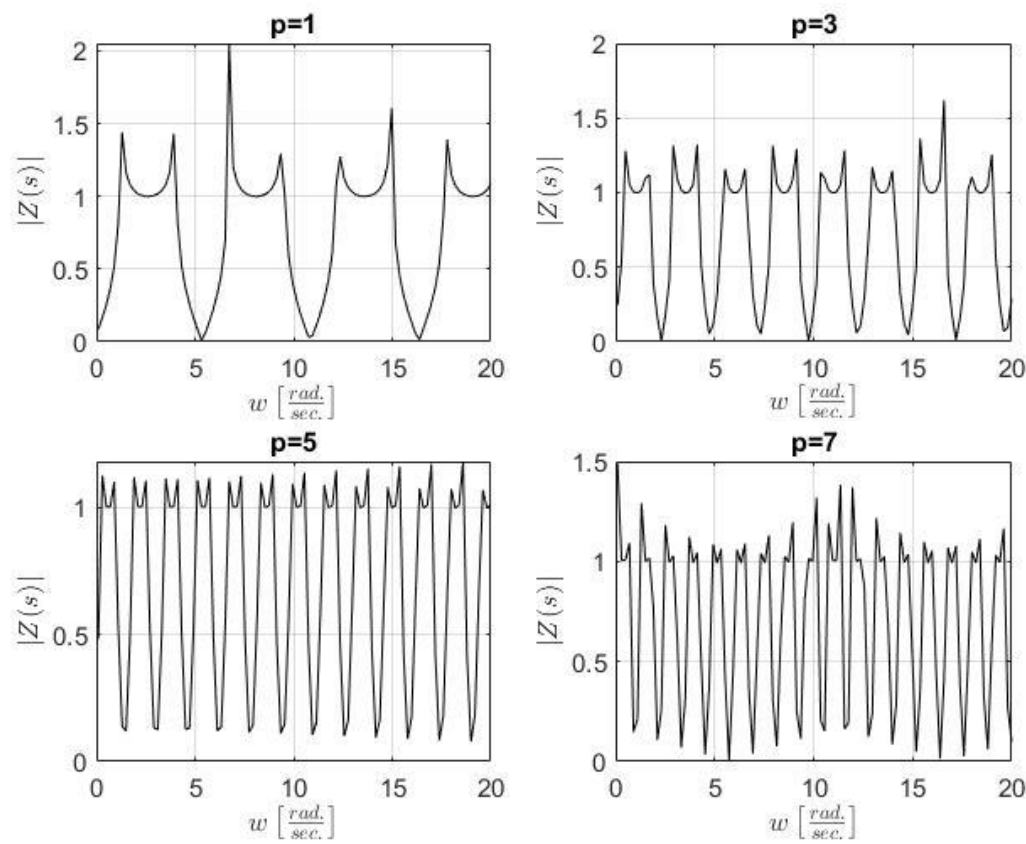

Figure 6. Frequency magnitude graphics of $Z(s)$ function obtained in Theorem 2 for odd values of $p$.

\section{Conclusions}

In this work, Schwarz Lemma has been used for boundary analysis of DPIFs by analyzing the derivative of DPIF at the origin. Within the manuscript, a lemma and two theorems have been presented and lower boundaries have been obtained for $\left|Z^{\prime}(0)\right|$. Performing sharpness analysis of obtained inequalities, three DPIFs corresponding to 
three generic filter structures have been obtained. According to simulation results, different filter structures can be obtained by utilizing the resulting DPIFs. Simple filter structures are determined when the DPIFs obtained in Lemma 1 and Theorem 1 are utilized. On the other hand, an oscillating DPIF is obtained in Theorem 2. Various filter structures showing distinct characteristics in frequency domain can be determined by performing analyses presented in this study.

\section{Conflict of Interest}

No conflict of interest was declared by the authors.

\section{References}

Boas, H. P., 2010. Julius and Julia: Mastering the Art of the Schwarz lemma. The American Mathematical Monthly, 117 (9), 770-785.

Dineen, S., 2016. The Schwarz Lemma. Courier Dover Publications, USA.

Dubinin, V. N., 2004. The Schwarz inequality on the boundary for functions regular in the disk. Journal of Mathematical Sciences, 122 (6), 3623-3629.

Hazony, D., 1963. Elements of network synthesis. Reinhold Publishing Corporation, New York, USA.

Kresin, G., Maz'ja, V. G., 2007. Sharp real-part theorems. Berlin: Springer.

Krueger, R. J., Brown, D. P., 1969. Positive real derivatives of driving point functions. Journal of the Franklin Institute, 287 (1), 51-60.

Mercer, P. R., 1997. Sharpened versions of the Schwarz lemma. Journal of Mathematical Analysis and Applications, 205 (2), 508-511.

Mercer, P. R., 2018a. Boundary Schwarz inequalities arising from Rogosinski's lemma. Journal of Classical Analysis, 12, 93-97.

Mercer, P. R., 2018b. An improved Schwarz Lemma at the boundary. Open Mathematics, 16 (1), 1140-1144.

Osserman, R., 2000. A sharp Schwarz inequality on the boundary. Proceedings of the American Mathematical Society, 128 (12), 3513-3517.

Örnek, B. N., Düzenli, T., 2018. Boundary Analysis for the Derivative of Driving Point Impedance Functions. IEEE Transactions on Circuits and Systems II: Express Briefs, 65 (9), 1149-1153.

Örnek, B. N., Düzenli, T., 2019. Schwarz lemma for driving point impedance functions and its circuit applications. International Journal of Circuit Theory and Applications, 47 (6), 813-824.

Örnek, B. N. (2015). Caratheodory's inequality on the boundary. The Pure and Applied Mathematics, 22 (2), 169-178.

Reza, F. M., 1962. A bound for the derivative of positive real functions. SIAM Review, 4 (1), 40-42.

Van Der Pol, B., 1937. A new theorem on electrical networks. Physica, 4 (7), 585-589. 